\title{
Uji resistensi nyamuk aedes aegypti terhadap sipermetrin $0,05 \%$ dipelabuhan Sungai Duku dan Bandara Sultan Syarif Kasim II Pekanbaru
}

\author{
Dedes Handayani ${ }^{1}$, Zuhirman ${ }^{2}$, Ridwan Manda Putra ${ }^{3}$ \\ ${ }^{1}$ PNS Kantor Kesehatan Pelabuhan Kelas II Pekanbaru. \\ ${ }^{2}$ Dosen Fakultas Kedokteran Universitas Riau. \\ ${ }^{3}$ Dosen Magister Ilmu Lingkungan Pascasarjana Universitas Riau. \\ *Correspondent email : dedeshandayani1983@gmail.com
}

Diterima: 17 Februari 2021 | Disetujui: 28 Februari 2021 | Diterbitkan: 28 Februari 2021

\begin{abstract}
Control of use of chemical insecticides is one way to reduce the vector borne disease dengue hemmorrhagic fever (DHF)which are caused by the mosquito Aedes aegypti. This study aims to determine the susceptibility status of Aedes aegypti to cypermethrin insecticide, the differences susceptibility status in the Duku River Port and Sultan Syarif Kasim Airport Pekanbaru. This study was an descriptif study with cross-sectional design. Egg and Larva Aedes aegypti mosquito sample collected from ovitrap and larva-place from Duku River Port area and Sultan Syarif Kasim II Airport. Test of susceptibility to cypermethrin $0.05 \%$ was done using impregnated paper refers to the WHO method, T independent test to considaret susceptibility status different both area. The result showed that Ae. aegypti in Duku River Port area and Sultan Syarif Kasim II airport areas have been toleran cypermethrin $0.05 \%$. There is no difference in the susceptibility of cypermethrin 0,05\% to the population of Aedes aegypti in Duku River Port and Sultan Syarif Kasim II Airport.
\end{abstract}

Keywords: sussceptibility test; aedes aegypti; duku river port; sultan syarif kasim ii airport; $t$ independent tes

Demam Berdarah Dengue (DBD) merupakan satu di antara masalah kesehatan yang utama di Indonesia. Jumlah penderita DBD meningkat dari tahun ke tahun seiring dengan meningkatnya mobilitas dan kepadatan penduduk di Indonesia. Pada Tahun 2016 jumlah kasus DBD di Indonesia adalah 204.171 kasus dengan jumlah kematian sebanyak 1.598 orang. Jumlah kasus DBD Tahun 2016 meningkat dari tahun 2015 (129.650 kasus). Jumlah kematian akibat DBD Tahun 2016 juga meningkat dari Tahun 2015 (1.071 kematian). Incidence rate (IR) atau angka kesakitan DBD Tahun 2016 juga meningkat dari Tahun 2015 yaitu 50,78 menjadi 78,85 per 100.000 penduduk. Pada Tahun 2016 incidence rate (IR) di Provinsi Riau sebesar 64,14 per 100.000 penduduk (Kemenkes RI, 2017).

Penyebaran penyakit erat kaitannya dengan meningkatnya mobilitas penduduk dan sejalan dengan semakin lancarnya hubungan transportasi. Pelabuhan dan Bandara merupakan pintu gerbang lalulintas orang, barang, dan alat angkut baik dari luar dan dalam negeri maupun antar pulau. Mobilitas orang dan barang semakin cepat melebihi masa inkubasi penyakit menular. Kondisi tersebut berpengaruh terhadap resiko penularan penyakit secara global (Kemenkes RI, 2007). Menurut Peraturan Menteri Kesehatan RI No.50 Tahun 2017 tentang Standar Baku Mutu Kesehatan Lingkungan dan Persyaratan Kesehatan untuk Vektor dan Binatang Pembawa Penyakit serta Pengendaliannya, wilayah pelabuhan dan bandara harus bebas dari vektor penular penyakit. Salah satu program pemberantasan vektor DBD adalah dengan metoda kimia yakni penggunaan insektisida. Insektisida merupakan golongan pestisida terbesar yang digunakan dalam program pemberantasan hama dan vektor penyakit serta berbagai jenis serangga pengganggu (Kemenkes, 2012). Penggunaan insektisida sintetik (kimia) dikenal sangat efektif, relatif murah, mudah dan praktis (Basri dan Hamzah, 2017) tetapi berdampak negatif terhadap lingkungan hidup (Sudrajat, 2010). Salah satu dampak negatif diantaranya adalah timbulnya resistensi pada hewan sasaran.

Hal ini terjadi karena nyamuk Aedes aegypti dan dengue lainnya mampu mengembangkan sistem kekebalan terhadap insektisida yang sering dipakai. Serangga yang telah resisten akan bereproduksi dan akan mengalami perubahan genetik yang menurunkan keturunan resisten (filialnya), yang pada akhirnya akan meningkatkan proporsi vektor resisten dalam populasi (Kemenkes RI, 2012). Resistensi terjadi apabila secara alami terjadi mutasi genetika yang memungkinkan proporsi kecil dari populasi (kurang dari 1 per 100.000 individu) mampu bertahan dan tetap hidup akibat insektisida (Kemenkes RI, 2012). 


\section{SEHATI}

Jurnal Kesehatan

Vol 1, No 1, Februari 2021, p. 16-21

e-ISSN : 2775-6963 | p-ISSN : 2775-6955

Sejalan dengan penelitian yang dilakukan oleh Wahyudin (2009) tentang uji kerentanan Nyamuk Aedes aegypty terhadap insektisida yang digunakan Kota Cimahi Provinsi Jawa Barat didapatkan Nyamuk Aedes aegypti telah resistan terhadap insektisida organofosfat dan toleran terhadap insektisida piretroid. Menurut penelitian yang dilakukan oleh Widarti dkk (2011) pada nyamuk Aedes aegypti di Jawa Tengah dan daerah Istimewa Yogyakarta yang juga telah resisten terhadap insektisida Malathion 0,8\%, Bendiocarb 0,1\%, Lamhdasihalotrin 0,05\%, Siperrmethrin 5\%, Deltamethryin 0,05\% dan Etofenproks 0,5\% (Widarti dkk,2011). Hasil uji kerentanan Aedes sp terhadap Malathion oleh Soenjono, JS Tahun 2011 di Wilayah Kerja Kantor Kesehatan Pelabuhan Bandar Udara Sam Ratulangi Manado juga menyebutkan telah terjadi resistensi Aedes aegypti terhadap insektisida malathion dengan jumlah persentase kematian nyamuk $0 \%$.

Berdasarkan data awal dari Kantor Kesehatan Pelabuhan Kelas II Pekanbaru kegiatan pengendalian vektor yang dilakukan pada Pelabuhan Sungai Duku dan Bandara Sultan Syarif Kasim II Pekanbaru berupa fogging rutin setiap 3 bulan, kegiatan preventif tersebut dilakukan tanpa memperhatikan ada tidaknya kasus DBD. Insektisida yang digunakan oleh Kantor Kesehatan Pelabuhan Kelas II Pekanbaru adalah Sipermetrin. Menurut Peraturan Menteri Kesehatan RI No.50 Tahun 2017 tentang Standar Baku Mutu Kesehatan Lingkungan dan Persyaratan Kesehatan untuk Vektor dan Binatang Pembawa Penyakit serta Pengendaliannya Pengendalian vektor dengan menggunakan insektisida harus dilakukan uji kerentanan insektisida. Uji kerentanan insektisida diwilayah Pelabuhan dan Bandara wajib dilaksanakan minimal 1 (satu) kali setahun. Penggunaan Sipermetrin sebagai insektisida telah digunakan sejak Tahun 2016 namun belum diuji status kerentanannya (KKP Pekanbaru, 2019).

Mengingat penggunaan insektisida yang berbeda-beda pada suatu daerah akan menghasilkan resistensi yang beda pula maka perlu dilakukan uji resistensi Nyamuk Aedes aegypti terhadap insektisida yang digunakan saat ini di Pelabuhan Sungai Duku dan Bandara Sultan Syarif Kasim II Pekanbaru. Penentuan status resistensi vektor nyamuk secara berkala sangat diperlukan untuk mendapatkan data dasar deteksi lebih lanjut dan monitoring terjadinya resistensi sehingga penggunaan insektisida, efektif dalam pengendalian vektor.

\section{METODE PENELITIAN}

Metode pada penelitian ini adalah deskriptif dengan desain penelitian cross sectional study. Variabel bebas adalah nyamuk Aedes aegypti yang terpapar insektisida di Pelabuhan Sungai Duku dan Pelabuhan Sultan Syarif Kasim II Pekanbaru, sedangkan variabel terikat yaitu status kerentanan Nyamuk Aedes aegypti. Populasi penelitian ini adalah populasi Nyamuk Aedes aegypti di wilayah Pelabuhan Sungai Duku dan Bandara Sultan Syarif Kasim II Pekanbaru. Sampel pada penelitian ini 250 ekor Nyamuk Aedes aegypti betina dewasa diambil dari nyamuk yang dibiakkan hingga dewasa dari larva Aedes aegypti yang diperoleh di wilayah Pelabuhan Sungai Duku dan Bandara Sultan Syarif Kasim II Pekanbaru, masing-masing lokasi penelitian 125 ekor. Metode uji resistensi mengacu pada kriteria Uji Susceptibility World Health Organization (WHO, 2013). Uji susceptibility menurut WHO (2013), kematian 99\%-100\% adalah rentan/susceptible, kematian $80 \%-98 \%$ adalah toleran dan kematian $<80 \%$ adalah resisten. Analisa perbedaan status kerentanan nyamuk di Pelabuhan Sungai Duku dan Bandara Sultan Syarif Kasim II Pekanbaru menggunakan uji statistik yakni uji T Independent.

\section{HASIL DAN PEMBAHASAN}

\section{Pengumpulan Telur dan Jentik Nyamuk Aedes aegypti}

Telur Nyamuk Aedes aegypti dikumpulkan dari ovitrap yang telah ditempatkan disejumlah titik pada area pelabuhan Sungai Duku dan Bandara Sultan Syarif Kasim II Pekanbaru. Sedangkan jentik dikumpulkan dari area perkantoran dan area perumahan di ekitar Pelabuhan Sungai Duku dan Bandara Sultan Syarif Kasim II di bantu oleh kader Juru Pemantau Jentik (Jumantik) Kantor Kesehatan Pelabuhan Kelas II Pekanbaru.

Pengumpulan jentik-jentik disekitar perumahan diperoleh dari tempat-tempat perkembangbiakan nyamuk seperti bak mandi, ember, ban bekas dan tong sampah. Telur nyamuk serta jentik yang telah dikoleksi di Pelabuhan Sungai Duku dan Bandara Sultan Syarif Kasim II Pekanbaru di bawa ke laboratorium Kantor Kesehatan Pelabuhan Kelas II Pekanbaru untuk dibiakkan menjadi nyamuk dewasa. 
Uji Resistensi Nyamuk Aedes aegypti terhadap Sipermetrin 0,05\% di Lokasi Penelitian

Tabel 1. Uji Resisteni pada Nyamuk Uji

\begin{tabular}{ccccc}
\hline Lokasi Penelitian & Jumlah & \multicolumn{2}{c}{ Impregnated paper Sipermetrin } & \multirow{2}{*}{ Keterangan } \\
\cline { 3 - 4 } & Nyamuk Uji & \multicolumn{2}{c}{$05 \%$} & \\
\cline { 3 - 4 } & & Jumlah & Persentase & \\
Pelabuhan Sungai Duku & 100 & Nyamuk Mati & Kematian & \\
Bandara Sultan Syarif Kasim II & 100 & 83 & $83 \%$ & Toleran \\
\hline
\end{tabular}

Tabel 2. Uji Resitensi pada Nyamuk Kontrol

\begin{tabular}{cccc}
\hline Lokasi Penelitian & Jumlah Nyamuk & \multicolumn{2}{c}{ Impregnated paper tanpa insektisida } \\
\cline { 3 - 4 } & Kontrol & Jumlah & Persentase Kematian \\
Pelabuhan Sungai Duku & 25 & Nyamuk Mati & $0 \%$ \\
Bandara Sultan Syarif Kasim II & 25 & 0 & $4 \%$ \\
\hline
\end{tabular}

Pada Tabel 2 dapat dilihat bahwa kematian nyamuk kontrol di Pelabuhan Sungai Duku Pekanbaru adalah $0 \%$ maka perhitungan resistensi dapat dihitung dengan rumus :

$$
\begin{aligned}
& x=\frac{\text { jumlah nyamuk yang mati }}{\text { Jumlah seluruh sampel }} \times 100 \% \\
& x=\frac{83}{100} \times 100 \% \\
& x=83 \%
\end{aligned}
$$

Pada tabung kontrol di Bandara Sultan Syarif Kasim II Pekanbaru, terdapat kematian 1 ekor nyamuk dengan persentase kematian sebesar $4 \%$. maka perhitungan resistensi harus dikoreksi dengan rumus Abbot :

$$
\begin{aligned}
& x=\frac{\% \text { kematian nyamuk uji-\% kematian nyamuk kontrol }}{100-\% \text { kematian nyamuk kontrol }} \times 100 \% \\
& \mathrm{x}=\frac{82 \%-4 \%}{100-4 \%} \times 100 \% \\
& \mathrm{x}=81,25 \%
\end{aligned}
$$

Berdasarkan hasil uji resistensi Nyamuk Aedes aegypti terhadadap Sipermetrin di Bandara Sultan Syarif Kasim II Pekanbaru diperoleh nilai mortalitas $81,25 \%$ dan hasil uji resitensi di Pelabuhan Sungai Duku 83\% yang berarti bahwa nyamuk Aedes aegypti telah toleran terhadap Insektisida Sipermetrin 0,05\%. Toleran berdasarkan kriteria WHO yakni mortalitas $80 \%$ - $98 \%$.

Menurut Sucipto (2015) proses terjadinya penurunan kerentanan (resistensi) pada beberapa serangga termasuk nyamuk dapat dipengaruhi oleh 3 faktor, yaitu:

1. Faktor genetik, diketahui adanya sejumlah gen yang berperan dalam pengendali resisten (R-gen), baik dominan atau resesif, homozygote maupun heterozygote yang terdapat pada nyamuk maupun serangga lainnya. Faktor genetik seperti gen-gen yang menjadi pembentukan enzim esterase, yang dapat menyebabkan resistensi serangga terhadap insektisida organofosfat dan pyrethroid. Faktor genetik lain seperti adanya gen knock down resistence (kdr) sehingga serangga resisten terhadap insektisida.

2. Faktor biologis, meliputi biotik (adanya pergantian generasi, perkawinan monogamy atau poligamy dan waktu berakhirnya perkembangan setiap generasi pada serangga di alam), perilaku serangga misalnya: migrasi, isolasi, monofagi atau polifagi serta kemampuan serangga di luar kebiasaannya dalam melakukan perlindungan terhadap bahaya atau perubahan tingkah laku. 


\section{SEHATI}

Jurnal Kesehatan

Vol 1, No 1, Februari 2021, p. 16-21

e-ISSN : 2775-6963 | p-ISSN : 2775-6955

3. Faktor operasional, meliputi bahan kimia yang digunakan dalam pengendalian vektor (golongan insektisida, kesamaan target dan sifat insektisida yang pernah digunakan, persistensi residu dan formulasi insektisida yang digunakan) serta aplikasi insektisida tersebut di lapangan (cara aplikasi, frekuensi dan lama penggunaan).

Pada populasi nyamuk Aedes aegypti di Pelabuhan Sungai Duku dan Bandara Sultaan Syarif Kasim II Pekanbaru telah terjadi toleransi. Uji resistensi yang dilakukan adalah uji resistensi dengan metoda konvensional dengan impregnated paper Sipermetrin 0,05\%. Uji Biokimia atau deteksi enzimatis dan deteksi gen secara molekuler tidak dilakukan.karena keterbatasan peneliti serta sarana yang ada di Pekanbaru.

Status toleransi nyamuk Aedes aegypti di Pelabuhan Sungai Duku daan Bandara Sultan Syarif Kaasim II Pekanbaru juga diduga karena faktor genetik, faktor biologis dan faktor operasional. Penggunaan insektisida yang terus menerus di Pelabuhan Sungai Duku dan Bandara Sultan Syarif Kasim II Pekanbaru yakni dengan melakukan penyemprotan/fogging sebanyak 4 kali dalam setahun meskipun tidak terjadi wabah Demam Berdarah Dengue. Menurut Kepala seksi Pengendalian Resiko Lingkungan Kantor Kesehatan Pelabuhan Kelas II Pekanbaru fogging rutin dilakukan dalam upaya mencapai amanat Menteri Kesehatan RI No.50 Tahun 2017 tentang Standar Baku Mutu Kesehatan Lingkungan dan Persyaratan Kesehatan untuk Vektor dan Binatang Pembawa Penyakit serta pengendaliannyayang menyatakan bahwa wilayah pelabuhan dan bandara harus bebas dari vektor penyakit.

Berdasarkan penelitian Sayono, S, dkk (2012) penggunaan insektisida dalam masyarakat berupa fogging dan penggunaan insektisida rumah tangga, dengan frekuensi fogging berkisar antara 1-6 kali per tiga tahun, dengan rerata 3,57 kalitahun, dengan rerata 1,38 dan penggunaan insektisida rumahan yang digunakan sebanyak $1-7$ kali seminggu dengan rerata 5,3 kali dapat meningkatkan toleransi sebesar 32,5\%.

Terjadinya resistensi atau toleransi dipengaruhi beberapa faktor, terutama penggunaan inektisida dalam waktu yang lama (Georghio and Melon, 2013).Menurut Sukesi (2013) resistensi akibat operasional juga dapat terjadi akibat kesalahan dosis insektisida pada saat fogging. Kesalahan dosis bisa berupa dosis yang terlalu rendah atau dosis terlalu tinggi. Menurut Kementrian kesehatan (2012), terjadinya resistensi Aedes aegypti di suatu wilayah salah satunya karena pemanfaatan insektisida rumah tangga dari kelompok pirethroid sintetik yang sangat intensif digunakan masyarakat untuk mengendalikan nyamuk.

Toleransi Sipermetrin 0,05\% terhadap populasi Nyamuk Aedes aegypti di Pelabuhan Sungai Duku dan Bandara Sultan Syarif Kasim II Pekanbaru juga diduga akibat faktor genetik. Hasil penelitian Widiastuti dkk Tahun 2014 di Kabupaten Klaten menunjukkan hasil bahwa 59 \% nyamuk mengalami heterozigot (V/G) dan $18,2 \%$ nyamuk $18,2 \%$ nyamuk mengalami homozigot (G/G). Hal ini menunjukkan bahwa telah terjadi mutasi gen. Hal yang sama juga diteliti oleh Ghifari dkk (2012), dimana terjadi mutasi titik Val10161le serta tidak terjadi mutasi titik Val1016Gly gen VGSC. Mutasi Val1016 gen VGSC Aeaegypti ssebagai penanda resistensi yang bersifat target sitepada populasi nyamuk Aedes aegypti di suatu wilayah.

Toleransi Sipermetrin 0,05\% terhadap Nyamauk Aedes aegypti di Pelabuhan Sungai Duku dan Bandara Sltan Syarif Kasim II Pekanbaru juga diduga akibat faktor biologis. Sipermetrin dapat menembus lapisan kitin dan melalui limfe, dan lipid saluran syaraf akan sampai pada sistem saraf pusat serangga. Mula-mula akan terjadi rangsangan kemudian kelumpuhan lalu kematian. Pada penggunaan yang sering, terjadi galur yang resisten, yang dengan bantuan enzim DDT-dehidroklorinasi memutuskan $\mathrm{HCl}$ dari klorfenotan dan terbentuk zat 1,1-di- (p-klorfenil) 2,2-dikloreten (DDE) yang tak toksik bagi serangga (Siswandono, 2000).

Perkembangan toleransi populasi serangga vektor terhadap insektisida menurut David dan Gilles (2002) dipengaruhi multipel faktor yaitu genetik (adanya fi-ekuensi gen spesifik), operasional (tipe dan aplikasi insektisida) dan biologis (ukuran dan karakteristik populasi vektor). Munculnya resistensi vektor tidak melalui proses adaptasi secara gradual terhadap senyawa kimia toksik, tetapi melalui proses percepatan menurut hukum seleksi Darwin yang terjadi di alam. Seleksi terjadi karena terdapat proporsi kecil serangga yang mengalami mutasi genetik secara individual. Mekanisme protektif ini tergantung faktor genetik baik tunggal, resesif, sebagian dominan atau dominan dalam proses keturunan. Apabila individu serangga heterozygote, maka jarang muncul pada proses resistensi awal dalam suatu populasi serangga termasuk nyamuk. Namun heterozygote yang survive pada uji kerentanan (uji susceptibility) apabila kawin dengan heterozygote yang lain akan menghasilkan proporsi homozygote dengan tingkat resistensi yang tinggi. Apabila gen resisten homozygote dominan, resistensi akan menyebar secara cepat ke seluruh populasi. 


\section{SEHATI}

Jurnal Kesehatan
Vol 1, No 1, Februari 2021, p. 16-21

e-ISSN : 2775-6963 | p-ISSN : 2775-6955

Uji Beda Kerentanan Sipermetrin 0,05\%terhadap populasi Nyamuk Aedes aegypti di Pelabuhan Sungai Duku dan Bandara Sultan Syarif Kasim II Pekanbaru

Uji beda kerentanan di Pelabuhan Sungai Duku dan Bandara Sultan Syarif Kasim II Pekanbaru dilakukan dengan membandingkan data status resistensi nyamuk di kedua wilayah. Uji beda dihitung dengan uji statistik yakni dengan uji $\mathrm{T}$ Independent. Sebelum dilakukan uji $\mathrm{T}$ independent dilakukan uji kenormalan data dan uji homogenitas data. Dari perhitungan nilai $\mathrm{T}$ diperoleh nilai t hitung lebih kecil dari $\mathrm{t}$ tabel $(0,252<3,182)$. Dengan demikian Ho ditolak dan Ha diterima. Jadi kesimpulannya tidak terdapat perbedaan antara resistensi populasi nyamuk di Pelabuhan Sungai Duku dengan Populasi nyamuk di Bandara Sultan Syarif Kasim II Pekanbaru.

\section{KESIMPULAN}

Telah terjadi toleransi penggunaan Sipermetrin 0,05\% terhadap populasi Nyamuk Aedes aegyptidi Pelabuhan Sungai Duku berdasarkan uji susceptibility menggunakan impregnated paper standar WHO, dimana mortalitas Nyamuk Aedes aegypti adalah 83 \%. Telah terjadi toleransi penggunaan Sipermetrin 0,05\% terhadap populasi Nyamuk Aedes aegyptidi Bandara Sultan Syarif Kasim II berdasarkan uji susceptibility menggunakan impregnated paper standar WHO, dimana mortalitas Nyamuk Aedes aegypti adalah 81, $25 \%$. Tidak terdapat beda kerentanan Sipermetrin 0,05\% terhadap populasi Nyamuk Aedes aegypti di Pelabuhan Sungai Duku dan Bandara Sultan Syarif Kasim II Pekanbaru.

\section{UCAPAN TERIMAKASIH}

Penulis menyampaikan terimakasih kepada seluruh pihak yang membantu dalam kelancaran penelitian ini.

\section{DAFTAR PUSTAKA}

Basri, S. dan E. Hamzah, 2017. Penggunaan Abate dan Bacillus Thuringensis var. Israelensis di Kantor Kesehatan Pelabuhan Kelas II Samarinda Wilayah Kerja Sanggata Terhadap Kematian Larva Aedes sp. Al-Sihah: The Public Health Science Journal, 9(1).

David A. W and H. M. Gilles. H. M. " Essential Malariology" International Student Edition. Fourth Edition, London, York, New Delhi. . 2002. p. 159-166. 12. Darriet,F, P. Guillet, R.N. N'Guessan, J.MDent, D. 2000. Climate Change : Impact, Adaption and Vulnerability, Contribution of Working Grup II to the Fourth Asessment Reportof the Intergovermental Panel on Climate Change. Canbridge Unversity, UK

Georghio, G.P and R.B. Melon (2013). Pest Resistance to Pesticide. Plenum Press. New York

Kemenkes RI. 2007. Keputusan Menteri Kesehatan RI. No.431/Menkes/SK/IV/ 2007 tentang Pengendalian Resiko Kesehatan Lingkungan di Pelabuhan/Bandara/Pos Lintas Batas dalam rangka Karantina Kesehatan. Kementrian Kesehatan RI,Jakarta.

Kemenkes RI. 2012. Pedoman Penggunaan Insektisida (Pestisida) dalam Pengendalian Vektor. Kementrian Kesehatan RI,Jakarta.

Kemenkes RI. 2017. Pedoman dan Pengendalian Demam Berdarah Dengue di Indonesia. Kementrian Kesehatan RI, Jakarta

KKP Pekanbaru, 2019. Profil Kantor Kesehatan Pelababuhan Kelas II Pelanbaru Tahun 2019. Pekanbaru

Sayono S., D.Sumanto, D. Syafruddin, , 2012. Distribusi resistensi Nyamuk Aedes aegypti terhadap Insektisisda Sipermetrin di semarang. Lembaga Pengembangan Universitas Muhammadiyah Semarang, Semarang

Soenjono SJ. 2011. Status Kerentanan Nyamuk Aedes sp. (Diptera:Culicidae) Terhadap Malathion dan aktivitas enzim esterase non spesifik di Wilayah Kerja Kantor Kesehatan Pelabuhan Bandara Sam Ratulangi Manado

Sucipto,C.D., 2015. Manual Lengkap Malaria. Gosyen Publishing, Yogyakarta 
SEHATI

Jurnal Kesehatan
Vol 1, No 1, Februari 2021, p. 16-21 e-ISSN : 2775-6963 | p-ISSN : 2775-6955

Sudrajat. 2010. Bioprospeksi Tumbuhan Sirih Hutan (Piper Aduncum L) Sebagai Bahan Baku Obat Larvasida Nyamuk Aedes aegypti. Jurnal Bioprospek, Vol. 7 No. II September 2010.

Sukesi, T. 2013 Resistance Status of Aedes aegypti L. Against Orgafosfatase Larvacide (temefos), organofosfatase (malathion) and pyrethroid (Sipermetrin) insecticide in the Gedongkiwo Village, Yogyakarta. Public Health Faculty Diponegoro University, Semarang

Wahyudin. (2009). Uji Kerentanan Nyamuk Vektor Aedes aegypti Terhadap Insektisida yang Digunakan dalam Program Pengendalian Deman Berdarah Dengue (DBD) di Kota Cimahi Provinsi Jawa Barat (Tesis). Yogyakarta: Universitas Gadjah Mada

Widarti, Heriyanto, B, Buowono, D.T, Widiyastuti, U, Mujiono, Lasmiati, dan Yuliadi. 2011. The Resistence Map Of Dengue Haemorragic Fever Vektor Aedes Aegypti A Gains Organophospha Tes, Carrama Tes and Pyrethroid Insecticides In central Java and Yogyakarta Province. Buletin Peneliti Kesehatan, Vol. 39, No. 4,Januari 2011 